\title{
LA RESPONSABILIDAD SOCIAL A TRAVÉS DE LAS ONDAS UNIVERSITARIAS ESPAÑOLAS
}

\section{Social Responsibility through the Spanish University Radio Waves}

\section{A responsabilidade social através de ondas de universidade espanhola}

\author{
Pinto-Zúñiga, Regina. Universidad de Málaga (España) \\ reginapinto@uma.es
}

Martín-Pena, Daniel. Universidad de Extremadura (España)

danielmartin@unex.es

\section{Fecha de recibido: 15 de diciembre de 2015}

Fecha de aceptado: 24 de febrero de 2016

\section{RESUMEN}

La radio universitaria se construye con mecanismos por los cuales los estudiantes pueden aproximarse al mercado laboral, pero también como un medio en el que tiene cabida activa la sociedad. En este estudio nos planteamos el objetivo de analizar el impacto del concepto de responsabilidad social en las emisoras universitarias españolas para su mejor integración en el tejido social y universitario. Para ello, diseñamos una metodología basada en entrevistas a los responsables de las estaciones de radio universitarias españolas que emiten con regularidad. La mayoría de las estaciones analizadas ha ido incorporando esta forma de trabajar a la dinámica de sus emisoras. Esto da lugar a que los futuros profesionales de la comunicación contemplen como habitual y necesaria la colaboración de los ciudadanos para construir el discurso radiofónico, lo que revertirá en un futuro más conciliador entre personas y medios de comunicación.

Palabras clave: radio universitaria, responsabilidad social, comunicación alternativa, España. 


\begin{abstract}
College radio is built with mechanisms through which students can approach to the labor market, but it is also built as a media in which civil society can take an active part. The objective that we plant is to analyze the need to introduce and preserve the concept of social responsibility in the Spanish university radio stations for attaining the integration between the social system and the university. We designed a methodology based on interviews with those responsible for the Spanish college radio stations that broadcast regularly. Somehow, most of the radio stations analyzed have been incorporating this way of working to their daily basis, making the future professionals in the communication field to contemplate as usual and needed the citizens' cooperation in order to build the radiophonic speeches, which will revert into a more conciliatory future between people and media.
\end{abstract}

Keywords: college radio, social responsibility, alternative communication, Spain.

\title{
RESUMO
}

Rádio universitária é construído com mecanismos pelo qual os alunos podem abordagem ao mercado de trabalho, mas também como um meio em que a sociedade tem lugar ativo. Neste estudo nós levantamos o alvo de analisar o impacto do conceito de responsabilidade social nas estações de rádio universidade espanhola para sua melhor integração no tecido social e universidade. Para isso, desenha uma metodologia baseada em entrevistas com os responsáveis das estações de rádio universidade espanhola que emitem com regularidade. As estações mais analisadas incorporou esta maneira de trabalhar com a dinâmica de suas estações. Isso da lugar a profissionais da comunicação contempla como habitual e necessária a colaboração dos cidadãos para construir o discurso de rádio, que reverterá no futuro mais conciliador entre as pessoas e a mídia.

Palavras-chave: rádio da universidade, responsabilidade social, comunicação alternativa, Espanha.

\section{Introducción}

\section{El panorama de la radiodifusión en España y el tercer sector de la comunicación}

El inicio de la radiodifusión universitaria en España, al igual que en el resto de países del continente europeo, se dilata hasta bien entrada la segunda mitad del siglo XX, exceptuando los casos de Francia y Reino Unido, que fueron pioneros, en gran parte gracias al temprano desarrollo del movimiento de las radios asociativas y libres en los años 60 (Cheval y Sevilla, 2009). Según Vázquez (2012) este hecho puede relacionarse con los monopolios que 


\section{DISERTACIONES}

ESTUDIOS

Anuario electrónico de estudios en Comunicación Social

ISSN: $1856-9536$

Doi: dx.doi.org/10.12804/revistas.urosario.edu.co/disertaciones/a.4437

Volumen 10, Número 1 / Enero-junio 2017

Versión PDF para imprimir desde

http://revistas.urosario.edu.co/index.php/disertaciones

existieron en los medios de comunicación en la mayoría de estados europeos hasta bien entrado la última cuarta parte del siglo XX, así como con las dictaduras vividas en determinados países, que hasta su caída no permitieron cierta liberalización del mercado audiovisual.

Esta circunstancia ha repercutido de forma negativa en la construcción del tercer sector de la comunicación, que en el caso de España ha sido más acuciante. Poco o nada que ver con la realidad vivida en otros países del entorno, en los cuales la liberalización del mercado ha permitido aflorar determinadas iniciativas de este sector de la comunicación. Tal y como recoge Ortiz (2014) "en el caso de Francia, una Ley del Gobierno Mitterrand, en 1981 y 1982, normalizó la situación de las emisoras libres del denominado Tercer Sector Radiofónico permitiendo la creación e implantación definitiva de las catalogadas como radios associatives (libres y comunitarias)" (p. 27). Las emisoras de esta tipología, que dan respuesta a otro tipo de necesidades y ofrecen cobertura a otros públicos desfavorecidos e ignorados desde el punto de vista mediático; agrupan estaciones radiofónicas ciudadanas, escolares, universitarias y de colectivos sociales determinados (lingüísticos, culturales, indígenas, comunales, rurales, etc.).

En el caso de España al igual que sucede en la mayoría de países del entorno, el espectro radioeléctrico cuenta en la actualidad con tres modelos de gestión, que se entremezclan y conviven (Peñafiel, 2011):

- La radio comercial, o modelo de libre mercado. Es la radio financiada por la publicidad y cuyo objetivo primordial es la obtención de beneficios económicos y la primacía de los intereses comerciales. La radio comercial funciona como una empresa de comunicación, que busca alcanzar las máximas audiencias con el menor coste posible. Esta radio se basa en economías de escala, lo que le obliga a agruparse y trabajar en la formación de cadenas o redes. Da lugar a grandes grupos de comunicación que controlan la gran parte de los ingresos publicitarios.

- La radio pública, o modelo de radiodifusión de servicio público. Este modelo parte de la radiodifusión como un bien público que debe usarse para provecho de la nación y de los ciudadanos. Su fin es lograr el servicio público desde un punto de vista más institucional.

- La radio comunitaria, también llamada libre o asociativa. Este modelo surge como oposición explícita a los dos modelos previos y constituye el tercer sector de la comunicación. Este tipo de radiodifusión reivindica un mayor protagonismo de los oyentes como sujetos activos y participantes, y les ofrece incluso la posibilidad de controlar el propio medio. La comunidad que sustenta este tipo de radiodifusión puede ser de índole geográfica, pero también puede surgir por el agrupamiento en función de determinados intereses, de un idioma, de una cultura o de una etnia. No tienen ánimo de lucro, están al margen de cualquier grupo de presión organizado y son contrarios al monopolio y a la centralización de la comunicación. En este grupo ubicamos a las radios universitarias, pero con ciertas premisas, unas emisoras preocupadas por la conexión universidad-sociedad, el bien de interés público y la participación libre y amplia.

García (2013) también contempla esta clasificación en tres grandes sectores: el sector público, el sector privado mercantil, y el sector privado no lucrativo o tercer sector. Así, diferencia entre la actividad no lucrativa realizada por el sector público del privado, a la vez que distingue dos tipos de entidades privadas, convirtiendo al tercer sector en un espacio excesivamente heterogéneo que, como indica, está formado por actividades con más elementos diferenciales que comunes. Por eso, según el autor, existen radios que no se sienten reflejadas en la denominación de tercer sector audiovisual, ya que no recoge sus especificidades y las agrupa con otras emisoras de las que se sienten muy distintas. Es el caso de las radios universitarias, contempladas como experiencias que 


\section{DISERTACIONES}

ESTUDIOS

Anuario electrónico de estudios en Comunicación Social

ISSN: $1856-9536$

Doi: dx.doi.org/10.12804/revistas.urosario.edu.co/disertaciones/a.4437

Volumen 10, Número 1 / Enero-junio 2017

Versión PDF para imprimir desde

http://revistas.urosario.edu.co/index.php/disertaciones

tienen un encaje difícil dentro de esta forma de clasificar, ya que en algunos casos son promovidas por universidades públicas (primer sector), en otros son centros privados (segundo sector) y en otros casos son gestionadas por asociaciones vinculadas a la universidad (tercer sector).

El tercer sector de la radiodifusión en España no ha estado regulado hasta el año 2010, cuando se aprueba la Ley General de Comunicación Audiovisual (LGCA) (Ortiz, 2014). Hasta esa fecha el panorama legislativo dejaba por fuera toda posibilidad de reconocimiento jurídico a las estaciones radiofónicas de proximidad. Por ejemplo, Durán y Fernández (2005) realizaban esta clasificación de las emisoras desde el punto de vista legislativo:

- Radios legales. Dentro de estas podríamos realizar una doble distinción; por un lado, emisoras públicas (estatales, autonómicas o locales) que realizan una gestión directa de este servicio público y, por otro lado, emisoras privadas o comerciales, que habiendo obtenido la oportuna licencia por concesión administrativa, realizan una gestión indirecta de este servicio público en busca de su propio beneficio económico.

- Radios alegales. También calificadas como radios libres, constituyen lo que se conoce como el tercer sector. Generalmente, son emisoras de radio que carecen de licencia administrativa para emitir, pero que no tienen un carácter lucrativo, sino especialmente social y cultural, de ahí, que también se las conozca como radios culturales, educativas o asociativas. Por eso, aunque no posean licencia administrativa, no se les puede calificar como radios ilegales que están infringiendo la ley, sino más bien, como radios alegales, ya que desarrollan su propósito en un espacio no terminado de regular legalmente (hasta el año 2010).

- Radios ilegales. Se trata de emisoras sin licencia que operan como otras emisoras privadas o comerciales. Son empresas, que a diferencia de las emisoras alegales, buscan un beneficio económico por medio de esta actividad, pero sin haber obtenido la correspondiente autorización administrativa. Para distinguirlas de las radios libres o culturales, se las denomina también, radios piratas, ya que, en el sentido estricto del término, las primeras también pueden ser consideradas ilegales, según el ordenamiento jurídico actual.

Estos tres tipos de emisoras se encuentran en España en una especie de limbo legal que parece estar motivado por la limitación del espectro radioeléctrico, contemplado en la LGCA. Así, la base del problema se sitúa en la difusión radiofónica por ondas hertzianas o radiodifusión analógica, lo que supone un "freno al derecho constitucional de libertad de información cuando se trata de medios radiofónicos convencionales, pese a la inexistencia de ánimo de lucro, en un contexto en el que subyace la defensa de intereses empresariales" (Durán, 2011, p. 2). Sin embargo, desde la década de los 90, momento en el que se transfieren a las comunidades autónomas las competencias en materia de medios de comunicación, en algunas de ellas las emisoras de radio universitarias pueden disponer de un dial para emitir en FM.

Es ejemplo de lo anterior la aprobación del Decreto 174/2002, de 11 de junio, por el cual se regula el régimen de concesión de la Comunidad Autónoma de Andalucía para emisoras de radiodifusión sonora en ondas métricas con modulación de frecuencia y la prestación del servicio por parte de los concesionarios. Este decreto hace completamente legal y factible que una emisora de radio universitaria andaluza disponga de su propio dial en FM. El requisito fundamental es que se trate de emisoras culturales o sin ánimo de lucro. Por otra parte, Pinto-Zúñiga (2015) señala la inminente entrada en vigor de la nueva Ley Audiovisual de Andalucía, en la que tras meses de debate, en el que han participado de forma activa organizaciones no gubernamentales, así como las propias emisoras universitarias andaluzas, contempla en su anteproyecto a universidades públicas y centros de educación no universitarios como prestadores de servicio público (Pinto-Zúñiga, 2016). 


\section{DISERTACIONES}

ESTUDIOS

Anuario electrónico de estudios en Comunicación Social

ISSN: $1856-9536$

Doi: dx.doi.org/10.12804/revistas.urosario.edu.co/disertaciones/a.4437

Volumen 10, Número 1 / Enero-junio 2017

Versión PDF para imprimir desde

http://revistas.urosario.edu.co/index.php/disertaciones

En definitiva, aludimos a emisoras pertenecientes al primer sector de la comunicación cuando se trata de la radio pública, al segundo sector cuando nos referíamos a la radio privada o comercial y al tercer sector cuando hacemos referencia a las radios culturales, comunitarias, asociativas, educativas o libres, sin ánimo de lucro, siendo este último en el que suelen ubicarse las estaciones de radio universitarias en España. No obstante, tal y como indica Durán (2011), "aunque la legislación hace tiempo que ha incluido los tres tipos de medios, su referencia al tercer sector ha sido muy ambigua y no ha favorecido, en la práctica, su desarrollo y, ni siquiera, su legalización" (p. 4).

Por otra parte, en las emisoras del llamado tercer sector de la comunicación no debemos dejar de lado el conocimiento o las nociones que todo ser humano debería tener sobre justicia ecológica o ecosocial, o de buena vida que, como indica Barranquero (2012). Es una concepción que desborda los límites de un proyecto meramente económico, social o político, y que adquiere el carácter de paradigma regulador del conjunto total de la vida, tanto social como natural, conceptos que:

[...] aunque ya cuentan con algunos desarrollos en campos como la sociología, la ecología, el derecho o

la economía, aún no han permeado lo suficiente a la comunicación, si bien su enfoque es por definición interdisciplinario, crítico y normativo, en la línea de las reflexiones más avezadas de nuestra materia (p. 71).

\section{La radio universitaria, enlazada a la sociedad desde sus inicios}

Las emisoras universitarias viven de cara a la sociedad. Desde sus inicios esta ha sido una premisa irrenunciable. Bajo este prisma, el detonante de la radiodifusión universitaria de cariz social surgió en América Latina como consecuencia de la denominada Reforma de Córdoba de 1918 en Argentina, que dotaría a la universidad de algo de modernidad de la que carecía a inicios de siglo. Fue en junio de ese año cuando los jóvenes universitarios cordobeses iniciaron unas movilizaciones en favor de la democratización de la enseñanza, a las que se adherirán poco a poco todas las academias del entorno (Aguaded y Martín-Pena, 2013). Las reivindicaciones reformistas abogaban por la renovación de las estructuras y los objetivos de las universidades, la implementación de nuevas metodologías de estudio y enseñanza, el razonamiento científico frente al dogmatismo, la libre expresión del pensamiento, el compromiso con la realidad social y la participación del claustro estudiantil en el gobierno universitario (Rotman, 2014). Pero, lo que resultó trascendental para las futuras radios universitarias era uno de los principios por los que luchaba está reforma: la extensión universitaria y el compromiso con la sociedad, en busca de un fortalecimiento de la función social de la universidad, y la proyección al ciudadano de la cultura universitaria y la preocupación por los problemas nacionales. En definitiva, una verdadera incorporación de la difusión cultural y la extensión universitaria como tareas propias de las instituciones universitarias.

No debe resultar extraño que esto sucediera en Argentina, el país en el que apareció la primera estación universitaria latinoamericana en abril de 1924. Radio Universidad Nacional de La Plata, como sostiene Casajús (2011) surge estrechamente vinculada a la educación, la investigación e íntimamente ligada a la sociedad argentina. A fines de 1923, el entonces presidente de la Universidad Nacional de La Plata, doctor Benito Nazar Anchorena, ordenó la instalación de una oficina radiotelefónica de alta potencia, con el objetivo de transmitir las conferencias que se impartían en la universidad, y así contribuir a la labor de extensión que la universidad realizaba, desde que 


\section{DISERTACIONES}

ESTUDIOS

Anuario electrónico de estudios en Comunicación Social

ISSN: $1856-9536$

Doi: dx.doi.org/10.12804/revistas.urosario.edu.co/disertaciones/a.4437

Volumen 10, Número 1 / Enero-junio 2017

Versión PDF para imprimir desde

http://revistas.urosario.edu.co/index.php/disertaciones

así fue recogido en la Reforma de Córdoba. En su discurso de inicio de curso y de inicio del proyecto radiofónico el doctor Benito Nazar destacó que:

La Universidad de La Plata le corresponde la iniciativa de haber empleado una estación radiotelefónica no solo como excelente elemento de enseñanza e investigación para la Radiotécnica sino también para fines de divulgación científica, o sea, como elemento de extensión universitaria [...]. De tal modo, a la par que desarrolla una obra completa de difusión cultural, sirve para vincular más aún la Universidad con el medio social en que actúa, devolviendo con ventaja al país el esfuerzo que la Nación realiza para sostenerla.

En este sentido, Milito y Casajús (2011) apostillan que en Argentina estas emisoras han nacido:

Como un medio de divulgación de la labor de las universidades y de sus actividades académicas, científicas, estudiantiles e institucionales, a lo largo de los años las radios universitarias se han constituido y consolidado como canales de comunicación y difusión no solo de la comunidad universitaria, sino también del entorno social en el cual se encuentran (p. 2).

Años después, sería el turno de otros países del contexto como Colombia, Chile o México.

\section{Radio universitaria en España: entre las emisoras educativas y las estaciones comunitarias}

Para acercarse a la realidad de las emisoras universitarias en España es necesario acudir, por un lado, a las estaciones educativas, y por otro, a las radios comunitarias. Como afirman Martín-Pena y Contreras (2014), los orígenes de las emisoras universitarias han de buscarse en dichas radios educativas, debido al éxito que han tenido en nuestro país desde mediados de siglo pasado, creciendo en escuelas y centros educativos, preocupados por la motivación de su alumnado y por ofrecerles una forma diferente y complementaria del proceder didáctico, en pro de logros considerables en la formación integral de sus estudiantes.

La radio educativa forma parte de los cimientos de lo que sería después la radio universitaria, constituyendo desde sus inicios un instrumento didáctico novedoso e incentivador, además de una potente herramienta para conseguir la alfabetización mediática de la sociedad.

Según Merayo (2000), la acepción de radio educativa es tan amplia que cualquier definición queda incompleta. Sin embargo, y pese a que existen varios tipos de radios educativas, según el autor, todas parecen compartir un rasgo común: intentan alcanzar objetivos no comerciales y se orientan de forma especial y directa hacia una finalidad de carácter social sin ánimo de lucro. Señala además que a lo largo de la historia, la radio educativa adoptó tres direcciones distintas: "a) como apoyo directo a movimientos sociales, b) como extensión de la instrucción formal, y c) como instrumento para la educación no formal por medio de las radios populares y comunitarias".

Hoy en día, la radio universitaria en España, en la mayoría de los casos, no persigue el objetivo de ser una emisora educativa, a excepción del caso de la Universidad Nacional de Educación a Distancia (UNED). En el resto de los casos estudiados, nos encontramos con un modelo de radio evolucionado que comparte con esta primera definición de Merayo tan solo una de las premisas: que no tiene objetivos comerciales. Ya no se trata de formar al oyente, se trata de divulgar el conocimiento científico a la vez de crear una conexión entre la universidad y la sociedad.

Es importante realizar una diferenciación inicial para concretar más el concepto de radio universitaria. Esta primera aproximación a los orígenes de las emisoras universitarias quedaría incompleta si no abordamos la sinergia 
que existe con las radios comunitarias o asociativas. Según Chaparro (2004), la radio comunitaria está orientada a satisfacer las necesidades de comunicación de una comunidad o colectivo social, son medios constituidos desde una concepción horizontal en los que un equipo humano coordinador y la comunidad misma establecen las pautas de funcionamiento y las orientaciones para actuar, procurando la articulación social y el desarrollo humano. La participación en la radio comunitaria es activa, la comunidad misma se convierte en actor para garantizar la democratización de la palabra y del espectro radioeléctrico. Una radio comunitaria depende de una estructura horizontal donde las decisiones son compartidas por todos sus actores, racionalizando los objetivos propuestos en la promoción de la mejora de las condiciones de vida.

El fenómeno de las radios libres en España empezó casi en paralelo al inicio de la democracia y, sin embargo, al día de hoy, a pesar de que el ordenamiento jurídico las reconoce, dicha legislación sigue sin ser clara y aplicable. La primera emisora de este tipo fue Ona Lliure, que nació en Barcelona en 1979, aunque han destacado muchas otras como: Eguzki Irratia (Pamplona), Tas Tas Irratia Librea (Bilbao), Onda Latina (Madrid), Onda Verde (Madrid), Contrabanda (Barcelona) y Radio Topo (Zaragoza). Dentro de estas emisoras libres, podríamos a la vez diferenciar entre emisoras educativas, que son las que dependen de centros de enseñanza, centros culturales y casas de juventud, como es, claramente, el caso de las radios universitarias; y las radios asociativas, vinculadas a colectivos organizados mediante asociaciones.

Expuesta la definición de Chaparro, la pregunta sería la siguiente: ¿Es una emisora universitaria una radio comunitaria? Es una pregunta que es fácil formular, sabiendo que en Andalucía existe una normativa que permite que las actuales emisoras universitarias andaluzas emitan de forma legal a través de la FM. Son emisoras universitarias que operan bajo el paraguas que les brinda su condición de emisora cultural, por lo que por definición podría tratarse de radios asociativas. Sin embargo, a nuestro juicio, la estructura y organización vertical de estas emisoras impide que encajen, al ciento por ciento, dentro de la definición que aporta Chaparro.

Por otro lado, para la Asociación Mundial de Radios Comunitarias (Amarc), las emisoras objeto de nuestra investigación se encuentran dentro de una misma definición, como lo establece en su sitio web:

Radio comunitaria, radio rural, radio cooperativa, radio participativa, radio libre, alternativa, popular, educativa... Si las estaciones de radio, las redes y los grupos de producción que constituyen la Asociación Mundial de Radios Comunitarias se refieren a ellos mismos por medio de una variedad de nombres, sus prácticas y perfiles son aún más variados. Algunas son musicales, otras militantes y otras musicales y militantes [...]. Algunas estaciones pertenecen a organizaciones sin ánimo de lucro o a cooperativas cuyos miembros constituyen su propia audiencia. Otras pertenecen a estudiantes, universidades, municipalidades, iglesias o sindicatos. Hay estaciones de radio financiadas por donaciones provenientes de su audiencia, por organismos de desarrollo internacional, por medio de la publicidad y por parte de los gobiernos.

Todo apunta a que una emisora de radio universitaria debería contemplarse en gran medida desde el punto de vista de las personas que conviven en torno a la misma, para dar voz a la sociedad que rodea al centro de formación superior que la alberga, pero la pregunta es ¿realmente funciona así? ¿Cómo se formula la responsabilidad social en las estaciones de radio universitarias españolas? Esta investigación surge de lo planteado al respecto en la tesis doctoral Radios universitarias en España: plataformas de comunicación interactiva y redes de colaboración defendida en la Universidad de Huelva en 2013, que continúa en la tesis titulada La radio universitaria como medio de formación de futuros profesionales en España. Fundamentos para la creación de un modelo formativo integral 


\section{DISERTACIONES}

ESTUDIOS

Anuario electrónico de estudios en Comunicación Social

ISSN: $1856-9536$

Doi: dx.doi.org/10.12804/revistas.urosario.edu.co/disertaciones/a.4437

Volumen 10, Número 1 / Enero-junio 2017

Versión PDF para imprimir desde

http://revistas.urosario.edu.co/index.php/disertaciones

cuya defensa se ha efectuado en la Universidad de Málaga en 2015; dos trabajos que nos han servido como punto de partida.

\section{La responsabilidad social en las radios universitarias}

El discurrir histórico de la radio universitaria en España se divide en tres fases (Marta-Lazo y Martín-Pena, 2014). La primera fase, ubicada en el último cuarto del siglo XX, está marcada por la aparición del fenómeno de la radio universitaria y las primeras experiencias relacionadas con la misma, Radio UNED (1974) y Radio San Fernando (actual Radio Campus en la Universidad de La Laguna), surgida en 1987. Se trata de un desarrollo tardío, lento y pausado que culmina con la aparición de Radio Complutense, Radio Universidad de Salamanca y la 98.3 Radio, a partir de 1995.

La segunda fase, desarrollada en la primera década del siglo XXI, viene determinada por una consolidación y expansión del fenómeno de la radio universitaria, puesto que en poco más de diez años surgen una quincena de estaciones. Los motivos por los cuales sucede este boom son la evolución y uso de las TIC en las emisoras, la consolidación de las radios universitarias como plataforma de prácticas para el alumnado del área de Ciencias de la Comunicación, y el paulatino acercamiento a la sociedad.

La tercera etapa, en desarrollo actualmente, está caracterizada por ser un periodo determinado por la crisis económica que afecta a la sociedad española en general, y por ende, a la universidad. Nos encontramos ante una fase de replanteamiento y unión del fenómeno, que queda plasmado en 2011, con la creación de la Asociación de Radios Universitarias de España (ARU). En esta última fase es en la que menos emisoras universitarias se han creado, ya que han surgido apenas tres, todas ellas en universidades con estudios de Comunicación, "bajo el amparo y desarrollo de las TIC y en forma de plataformas hipermedias, que permiten la formación integral del alumnado de la rama de las ciencias de la información” (Marta-Lazo y Martín-Pena, 2014, p. 3).

La puesta en marcha de estas emisoras, como recogen Martín-Pena y Espino (2014), "suele tener como fin, en la mayoría de los casos, el abrir un canal de participación, donde se expresen inquietudes o se visualice el día a día de la institución, siempre extendiendo a la sociedad la cultura, la ciencia o el conocimiento general que la propia institución genera" (p. 28).

Pero ¿en qué consiste la responsabilidad social? Según Gaete (2011) existe una gran cantidad de elementos o características que componen las múltiples definiciones existentes sobre este concepto, así como diferentes criterios utilizados para intentar definir lo que significa aplicado al ámbito de las organizaciones, lo que aumenta su carácter difuso o confuso. De esta forma, llegamos al concepto de Responsabilidad Social Universitaria (RSU), que por su temática y ámbito se enmarca en lo que podría ser una definición acertada de la responsabilidad social en las radios universitarias:

Una especial atención tienen los planteamientos de la RSU que asignan un papel más activo de carácter reivindicativo y propositivo a las universidades, respecto de la solución a las principales problemáticas y necesidades sociales existentes en la actualidad, así como respecto de un desarrollo más sustentable en el futuro (Gaete, 2011, p. 117).

En este sentido, es en la segunda fase del desarrollo histórico de las emisoras de radio universitarias cuando, según Martín-Pena (2013), se produce una evolución en la mentalidad de las emisoras universitarias españolas a 


\section{DISERTACIONES}

ESTUDIOS

Anuario electrónico de estudios en Comunicación Social

ISSN: $1856-9536$

Doi: dx.doi.org/10.12804/revistas.urosario.edu.co/disertaciones/a.4437

Volumen 10, Número 1 / Enero-junio 2017

Versión PDF para imprimir desde

http://revistas.urosario.edu.co/index.php/disertaciones

raíz de la creación en 2007 de UniRadio Huelva, señalándola como un caso significativo en lo que al concepto de responsabilidad social se refiere. La estación universitaria de Huelva se convierte en la primera emisora de radio universitaria que emerge en Andalucía y que logra una concesión de dicha comunidad autónoma para operar como emisora cultural por medio de una asociación cultural. Es la primera emisora que realiza publicidad social y propone una programación que busca un acercamiento progresivo a la sociedad, asunto que se torna en factor clave del apogeo vivido por las emisoras universitarias en esos años, y que hará que muchas otras emisoras como OndaCampus o 98.3 Radio imiten parte de sus iniciativas. Según Vázquez (2012), la autorización administrativa lograda por UniRadio vino condicionada por la exigencia de una programación compuesta fundamentalmente de contenidos de carácter divulgativo, cultural, educativo y solidario, lo cual quedó reflejado en su reglamento de funcionamiento. Contreras (2012), por su parte, indica que la acción y la intervención social son parte importante de la parrilla de la emisora, para lo cual cuenta con la colaboración de colectivos que provienen tanto de adentro como de afuera de la comunidad universitaria. En este sentido, como señalan Contreras, Mairena y Aguaded (2014) desde el inicio se ha seguido una línea de trabajo en la que se construye una parrilla de programación de cariz social, bajo el nombre de Propósito Penélope que "se fundamenta en la responsabilidad de tejer una red de colaboración, solidaridad y trabajo colectivo en pos de lograr una sociedad más avanzada, basada en principios de solidaridad, igualdad, hermandad y justicia, para colaborar con la evolución de los valores sociales", toda una declaración de intenciones que convierte a esta estación universitaria en el paradigma del perfil social y de servicio público de las radios universitarias españolas.

Así, tal y como apunta López (2005), estamos ante un nuevo reto para la universidad, en el que se sustituye el concepto de proyección social, instaurándose el de responsabilidad social universitaria, de forma que la universidad no debe proyectarse a la sociedad, ahora es la universidad la que debe responder a demandas sociales específicas. Por otro lado, Casas (2005) subraya la importancia de la universidad para lograr una transformación de la sociedad, así como el progreso de la misma. En este sentido, Antequera y Obregón (2002), hablan del papel que tiene la radio en los procesos de desarrollo social y cultural, lo que lleva a la utilización de este medio como una herramienta de cambio, que promueva la participación y el protagonismo de los oyentes, y les permita ser los responsables de dicha transformación.

Al respecto de la transferencia social y del conocimiento que mencionamos, hay que destacar la función de servicio público que cumplen las emisoras universitarias, formando, informando e integrando al oyente como parte importante del medio (Aguaded y Contreras, 2011). Se consigue de esta forma que una persona perteneciente al tejido social "sienta como suyo un lugar que siempre se ha visto como reservado para las élites del conocimiento" (Contreras, 2012, p. 153) y logre un acercamiento efectivo entre la universidad y la sociedad. De esta manera, la radio universitaria se convierte en el cauce privilegiado de expresión de las inquietudes de la comunidad (González y Ramos, 2012).

Para López (2005), la radio es el mejor medio técnico interactivo para actuar en el entorno, ya que permite que se establezca un contacto directo entre el comunicador y la sociedad, y señala en este sentido que el comunicador es la propia universidad, el que se encarga de informar y aportar cultura además de difundir el saber que se genera en la misma. Al respecto, Casajús (2011) señala que las radios enmarcadas en el contexto universitario, y que funcionan con el respaldo de las universidades que las albergan, son parte del sistema de medios universitarios y a la vez se insertan en la sociedad, por lo que también conforman el sistema de medios de comunicación social. Esto 
da lugar a una auténtica "red de activos sociales de su entorno inmediato que encuentran un espacio de participación, enmendando los errores de comunicación del sistema comercial” (Contreras, Mairena y Aguaded, 2014, p. 128).

En cuanto al ámbito de la publicidad social, que también tiene su espacio en las estaciones de radio universitarias, García (2012) habla de la urgencia por realizar una reflexión profunda acerca de los valores de solidaridad, paz, derechos humanos, así como la importancia de colaborar con Organizaciones no Gubernamentales para el Desarrollo (ONGD), enfocándolo desde un punto de vista que cuestione y demuestre "las inconsistencias y efectos no deseados del modelo instrumental y utilitarista heredado de la comunicación comercial” (p. 1). Por tanto, resulta crucial concebir un medio de comunicación universitario basado en la formación de profesionales pero también de personas sobre las que recaerá la responsabilidad social en un futuro muy cercano.

[...] el ser humano precisa de la comunicación y la cultura, no para evolucionar en dirección alguna, sino

para pensar o articular antiguas y nuevas cosmovisiones y modos de vida, acordes con la solidaridad comunal y con la sostenibilidad de vida humana sobre la tierra (Barranquero, 2012, p. 67).

\section{Objetivos y metodología}

Mediante este artículo hemos profundizado en el concepto de responsabilidad social y hemos observado cómo se articula en las radios universitarias españolas al revisar las investigaciones realizadas a partir de 2013 por Martín-Pena y Pinto-Zúñiga. Para ello hemos estructurado la investigación en torno a un objetivo principal y uno específico:

Objetivo principal: analizar la responsabilidad social en las emisoras universitarias pertenecientes a la Asociación de Radios Universitarias de España (ARU).

Objetivo específico: observar los cambios acaecidos en torno al concepto de responsabilidad social en las emisoras de la ARU por medio de una comparativa de las programaciones de las emisoras en la temporada 20122013 hasta la temporada 2014-2015.

Para alcanzar cada uno de nuestros objetivos, y teniendo en cuenta que en España existen radios universitarias en una de cada tres universidades (Martín-Pena, 2013), hemos analizado veintidós de las veintisiete emisoras que pertenecen a la Asociación de Radios Universitarias de España (ARU) considerando que se trata de una muestra representativa que incluye todos los modelos de radio universitaria existentes en España recogidos por Fidalgo en su investigación de 2009. Hemos elegido la entrevista como herramienta para obtener la información necesaria, por medio de un cuestionario realizado a los responsables de cada una de las estaciones universitarias examinadas. Se trata de una muestra intencional, en una investigación de carácter cualitativo y cuantitativo. En la tabla 1 se pueden observar los responsables entrevistados, su cargo y emisora, así como la fecha de la entrevista. 


\section{DISERTACIONES}

ESTUDIOS

Anuario electrónico de estudios en Comunicación Social

ISSN: 1856-9536

Doi: dx.doi.org/10.12804/revistas.urosario.edu.co/disertaciones/a.4437

Volumen 10, Número 1 / Enero-junio 2017

Versión PDF para imprimir desde

http://revistas.urosario.edu.co/index.php/disertaciones

Tabla 1: Entrevistas muestra emisoras universitarias

\begin{tabular}{|c|c|c|}
\hline Nombre & Cargo y emisora & Fecha \\
\hline Leonor Real Adame & Coordinadora OndaCampus Radio & 16-dic-2014 \\
\hline Luis Javier Capote & Director Radio Campus & 08-ene-2015 \\
\hline Ignacio de Lorenzo Rodríguez & Director 98.3 Radio & 12-ene-2015 \\
\hline Paloma Contreras Pulido & $\begin{array}{l}\text { Presidenta Asociación Cultural UniRadio } \\
\text { Huelva }\end{array}$ & 14-ene-2015 \\
\hline Juan José Ceballos & Coordinador Europea Radio & 14-ene-2015 \\
\hline Miguel Ángel Ortiz & Coordinador InfoRadio UCM & 15-ene-2015 \\
\hline Elena Villegas Cara & Coordinadora Radio Universidad & 16-ene-2015 \\
\hline Sonia Martínez González & Coordinadora Radio UMH & 20-ene-2015 \\
\hline Carmen Revillo Rubio & Directora Programas de la UPV TV. & 21-ene-2015 \\
\hline María Carmen Aparisi & Coordinadora contenidos VOX UJI Radio & 22-ene-2015 \\
\hline Esther Benavides Junquera & Responsable UAL Radio & 23-ene-2015 \\
\hline Nereida López Vidales & Directora Radio UVA & 02-feb-2015 \\
\hline Carmen Marta Lazo & Directora Radio UniZAr.es & 03-feb-2015 \\
\hline Daniel Fernández Montero & Director RUAH Alcalá & 03-feb-2015 \\
\hline Remei Castelló Belda & Coordinadora Radio Universitat & 04-feb-2015 \\
\hline Isabel María García & Coordinadora iRadio UCAM & 05-feb-2015 \\
\hline Bruno Aceña Fernández & Director Radio USJ & 05-feb-2015 \\
\hline Manuel Sánchez Cid & Director Radio URJC & 10-feb-2015 \\
\hline Josep María Palau & Director UPF Ràdio & 17-feb-2015 \\
\hline Ángels Álvarez Villa & Codirectora Radio CEU & $17-$ feb-2015 \\
\hline Cristina Rodríguez Luque & Profesora colaboradora OnCEU Radio & 18-feb-2015 \\
\hline Julio Ángel Olivares & Director UniRadio Jaén & 20-feb-2015 \\
\hline
\end{tabular}

Fuente: elaboración propia.

\section{Resultados}

Cuando nos referimos a los proyectos de responsabilidad social de las emisoras universitarias nos centramos en su perfil de emisoras sociales y de servicio público. Por ello, hemos recabado información acerca de cómo estas estaciones fomentan o permiten la participación de asociaciones u ONG en la producción de los contenidos que se emiten. Se trata por lo tanto de observar la representación de programas de estas características dentro de la parrilla de la radio universitaria o de espacios reservados en determinados programas para dar cabida a distintos colectivos sociales que 'no tienen voz' en los medios comerciales (Aguaded y Contreras, 2011; Contreras, 2012 y Contreras, Mairena y Aguaded, 2014).

En la investigación realizada por Martín-Pena en la temporada radiofónica 2012-2013, la opción de reservar espacios en determinados programas es la más común en la mayoría de radios de la ARU. Por otra parte, en el caso 


\section{DISERTACIONES}

ESTUDIOS

Anuario electrónico de estudios en Comunicación Social

ISSN: 1856-9536

Doi: dx.doi.org/10.12804/revistas.urosario.edu.co/disertaciones/a.4437

Volumen 10, Número 1 / Enero-junio 2017

Versión PDF para imprimir desde

http://revistas.urosario.edu.co/index.php/disertaciones

de espacios o programas específicos de perfil social, destacan las parrillas de UniRadio Huelva, y UniRadio Jaén, que constituyen un ejemplo de apertura de este tipo de estaciones a asociaciones y a la ciudadanía en general. Es preciso destacar la labor de la emisora onubense con los internos del centro penitenciario provincial de Huelva por medio del programa radiofónico semanal El Zapato Roto que ha recibido y continúa recibiendo numerosos premios y reconocimientos nacionales y europeos, el último de ellos en noviembre de 2015, en los Premios de Comunicación Local otorgados por la Junta de Andalucía. Esta emisora ha conseguido cambiar la mentalidad en muchas de las estaciones universitarias españolas, tal y como reconoce en la entrevista el director de la 98.3 Radio de la Universidad de Navarra, Ignacio de Lorenzo Rodríguez:

UniRadio Huelva ha creado escuela, y ha concienciado socialmente nuestras actuaciones hacia la sociedad, nosotros hemos querido desarrollar su modelo de actuación social adaptado a nuestros objetivos.

Hemos empezado a realizar cuñas sociales para ONG y asociaciones en el marco de las prácticas de nuestros estudiantes.

En este sentido, también cabe señalar el proyecto de responsabilidad social que realiza Onda Campus de la Universidad de Extremadura. Una campaña de concienciación que se proyecta a lo largo del curso académico Operación Comprometida 9 (OC9), que se dedica cada mes a tratar uno de los objetivos del milenio de forma específica, utilizando entrevistas y microespacios. O las actuaciones realizadas por Vox UJI Ràdio que tiene programas específicos realizados por asociaciones como la Cruz Roja con un programa en el que se trabaja con personas con deficiencia psíquica: La hora de la palabra. O con la Fundación Patín, que trabaja el problema de las adicciones en el programa El hombre con rayos $x$ en los ojos.

En la investigación del año 2012, tan solo cuatro emisoras (Radio URJC, Radio USJ, Radio Universitat y OnCEU Radio) no tenían proyectos de este tipo, aunque en el caso de Radio Universitat, como reconoció su responsable, ya se estaba barajando la posibilidad de introducir en su parrilla de programación este tipo de programas o espacios, al observar la buena acogida que tiene este tipo de iniciativas para fortalecer el perfil social de nuestras emisoras.

La investigación llevada a cabo durante el curso 2014-2015 nos permite observar que en una emisora de radio universitaria priman diferentes aspectos, considerándose algunas estaciones con predominio en la formación, otras en lo institucional, otras en lo informativo y, en un reducido número, algunas se consideran eminentemente sociales. Mediante este trabajo hemos comprobado cuál es el grado de implicación de las emisoras universitarias analizadas con la sociedad que las rodea. Para ello consultamos a los responsables de las emisoras universitarias si colaboran de forma activa con ONG o asociaciones sin ánimo de lucro, y si introducen de alguna forma contenidos relativos a la responsabilidad social en la parrilla de la estación. En este sentido, la gran mayoría de las emisoras lo contempla como parte de sus funciones y de su cometido para con la sociedad, contabilizándose en un total de 21 emisoras que sí colaboran habitualmente con ONG o asociaciones de este tipo y tan solo una que no lo hace (ver gráfico 1). 


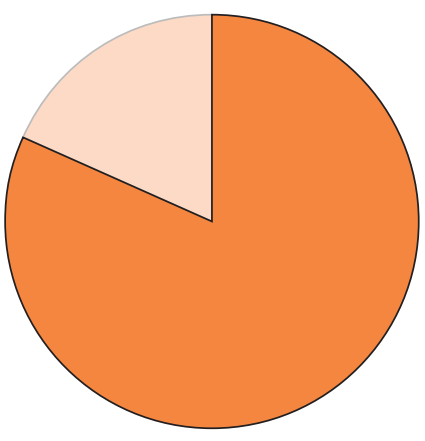

$81 \%$ Colabora

$18 \%$ No colabora

Fuente: elaboración propia.

Por otra parte, la investigación arroja que la responsabilidad social en las emisoras de radio universitarias españolas se lleva a cabo de tres formas diferentes: 1 ) desde fundaciones, asociaciones u organismos propios de la universidad que se reflejan de alguna manera en la radio universitaria; 2) en espacios específicos destinados a tal fin en la parrilla; y 3) con cuñas publicitarias. Tan solo una de las estaciones, OnCEU Radio, no presenta ningún tipo de contenidos sobre responsabilidad social (Ver gráfico 2).

Gráfico 2. Responsabilidad social temporada 2014-2015

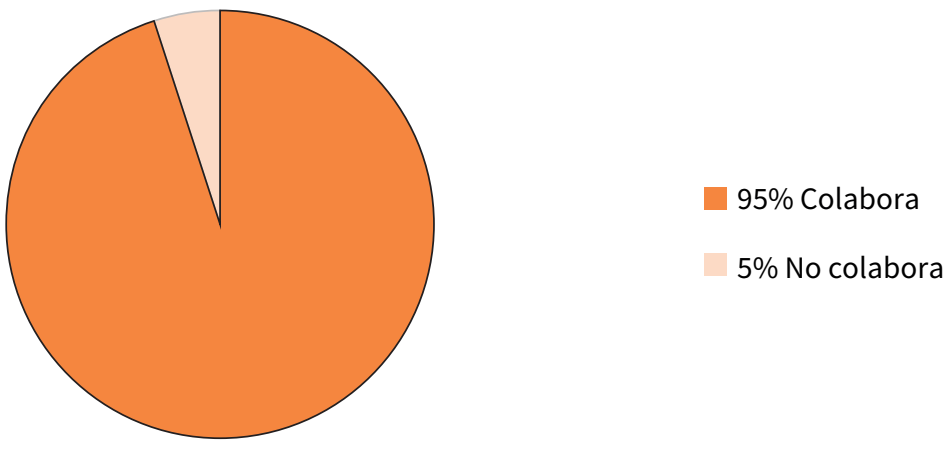

Fuente: elaboración propia.

Son siete las estaciones que llevan a cabo colaboraciones con organismos propios de la universidad (ver gráfico 3). Así observamos cómo la 98.3, emisora de la Universidad de Navarra, lo hace mediante iniciativas de la asociación Universitarios por la Ayuda Social. Por otra parte, en Europea Radio, de la Universidad Europea de Madrid, se efectúa con agencias que se incluyen dentro de Europea Media tales como Europea Adds o Europea Trad. En InfoRadio de la Universidad Complutense de Madrid se lleva a cabo con Solidarios, que es una asociación que opera dentro de la propia universidad, y en Radio UVA, de la Universidad de Valladolid, mediante la Oficina de Cooperación al Desarrollo y el Observatorio de Derechos 
Humanos. Por su parte, Radio USJ, propia de la Universidad de San Jorge, lo efectúa con la Fundación San Valero. Radio UPF, de la Universidad Pompeu Fabra, por medio de UPF Solidaria. En el caso de RUAH Alcalá, de la Universidad de Alcalá, en tiempos anteriores en los que la emisora gozaba de más participación, esta tarea se llevaba a cabo con la Asociación de Voluntariado Universidad de Alcalá mediante la difusión de los boletines que ellos remitían a la emisora.

\section{Gráfico 3. Responsabilidad social desde organismos propios de las universidades}

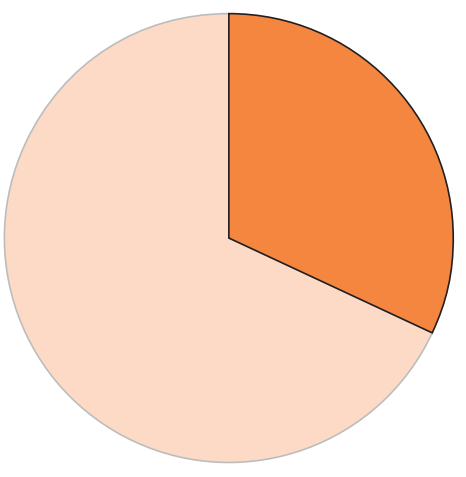

$32 \%$ Organismos propios

$68 \%$ De forma externa

Fuente: elaboración propia.

Otra forma de colaboración con el tercer sector es destinar espacios para ello en la parrilla de la emisora. Esta práctica la observamos en 18 de los casos (ver gráfico 4). En Radio Universidad de Salamanca se hace en forma de programas que colaboran con distintas asociaciones, así como en UPV Ràdio, InfoRadio, Radio UVA, Vox UJI Radio, RadioUniZar.es, iRadio UCAM, RUAH Alcalá, 98.3, Radio Campus o UPF Ràdio. En Radio Universitat se trata como tema transversal en programas e informativos y Radio URJC lo hace en forma de jornadas de emisión posterior y en Onda Campus, se continúa haciendo en Operación Comprometida 9 y en Radio USJ se realizan maratones solidarios varias veces al año.

Gráfico 4. Responsabilidad social en programas de las emisoras universitarias

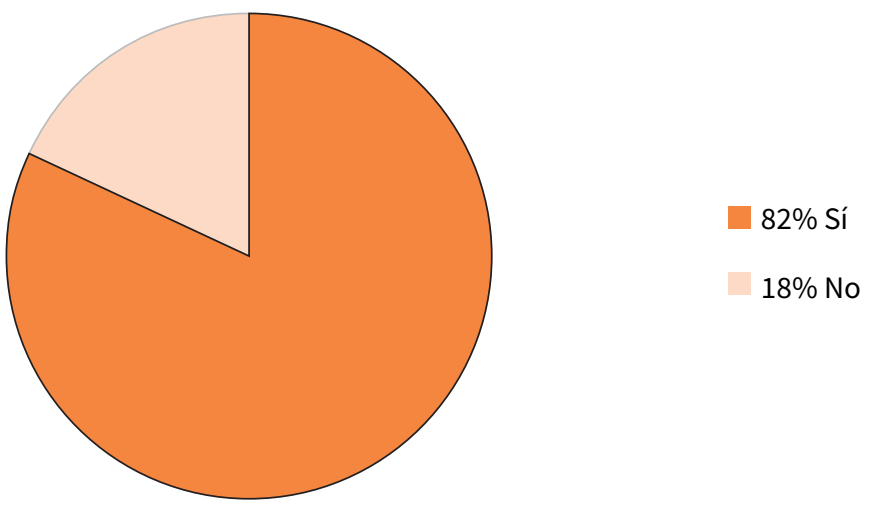

Fuente: elaboración propia. 
Merecen mención especial, tal y como se constata en la investigación de Martín-Pena en el curso 2012-2013, la labor de UniRadio Huelva donde, según su responsable Paloma Contreras Pulido, esta colaboración con el tercer sector "es la columna vertebral de la emisora, la idea era crear un medio en el que la sociedad tuviera la oportunidad de tener voz, devolver a la sociedad lo que la sociedad aporta, así como para la sociedad universitaria”. Destacamos también el caso de UniRadio Jaén, donde este tipo de contenidos forma parte del día a día de la estación universitaria, así como en Radio CEU donde, según su directora Ángels Álvarez Villa, "es un contenido que tiene mucha presencia en nuestra radio, les dedicamos reportajes, entrevistas, todo lo que podemos”. En Vox UJI Ràdio también se tiene en cuenta la inclusión de este tipo de contenidos, tal y como indica su coordinadora María Carmen Aparisi: "Colaboramos con ONG y fundaciones que realizan programas con nosotros y les emitimos cuñas de determinadas campañas, [...] aquella ONG que nos piden colaboración tienen las puertas abiertas”, y en la misma línea, en Radio UniZar.es, como apunta su directora Carmen Marta Lazo:

Colaboramos con un programa que se llama Con mucha miga, cada semana hacemos entrevistas a una

organización para dar a conocer cuáles son sus servicios. También dentro de un programa de innovación

docente que se llama Aprendizaje y Servicio de la Universidad de Zaragoza, en él grabamos distintos repor-

tajes y además de emitirlos en la emisora, los cedemos por si los quieren utilizar en sus páginas web.

Una tercera forma de colaboración es mediante cuñas promocionales de temática solidaria, con trece estaciones analizadas que hacen uso de esta herramienta publicitaria (ver gráfico 5). Al respecto podemos mencionar los casos de Radio UMH, de la Universidad Miguel Hernández, en la que se usan cuñas de dicha naturaleza para ayudar a las ONG con las que se firman convenios, o Radiouniversidad.es, también llamada UAL Radio de la Universidad de Almería, que incluso colabora grabando y editando las cuñas que emitirán las ONG con las que colaboran en otras estaciones.

Gráfico 5. Responsabilidad social por medio de cuñas sociales de las emisoras universitarias

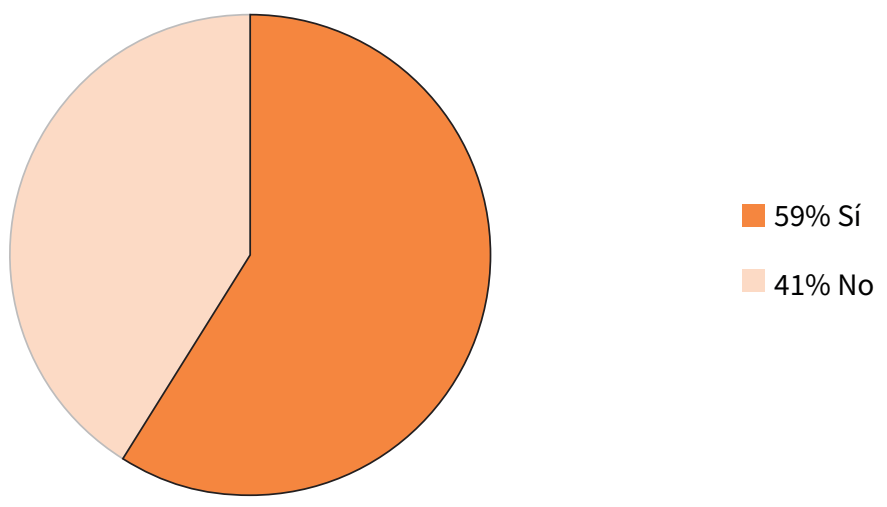

Fuente: elaboración propia. 


\section{Conclusiones}

Las radios universitarias españolas se sitúan en el tercer sector de la comunicación, muy cercanas a las premisas que promulgan las radios comunitarias, ambas ignoradas por el ordenamiento jurídico español (Ley General de Comunicación Audiovisual de julio de 2010), donde las emisoras universitarias no aparecen, y las estaciones comunitarias, aunque se mencionan de soslayo, quedan condenadas al más puro ostracismo mediático, sin opciones reales de acceso libre a las frecuencias de emisión, al no poder competir en igualdad de condiciones con los grandes grupos de comunicación. Así nos encontramos ante una paradoja comunicativa, ya que este tipo de emisoras, tanto las universitarias, objeto de estudio de esta investigación, como las comunitarias, representan el concepto de servicio público social en medio de un entramado de medios convencionales que tienen otro tipo de propósitos en su mayoría alejados de brindar una auténtica democratización de la comunicación.

En este sentido, una de las principales conclusiones de este estudio es el hecho que el concepto de responsabilidad social en las emisoras universitarias españolas ha cambiado de manera considerable a raíz de la creación en 2004 de la estación radiofónica de la Universidad de Huelva, UniRadio Huelva, una emisora que se torna en paradigma para el resto de estaciones universitarias españolas al nacer con el firme propósito de convertirse en abanderada del servicio público y de la democratización del acceso a la comunicación. Ofrece un altavoz desde la universidad a distintas asociaciones, colectivos sociales y personas individuales invisibilizadas por los grandes medios, y teje de esta manera un puente de diálogo de ida y vuelta entre la institución académica y la ciudadanía.

Este hecho ha supuesto un claro impulso para que la responsabilidad social en las emisoras universitarias se extienda como parte importante de las mismas y como una de las misiones que deben asumir para lograr una sinergia completa con su entorno. Dar voz a la sociedad que rodea a estas estaciones, así como impulsar y colaborar con las causas sociales, se ha convertido en parte del día a día de estas emisoras, que constituyen el lugar idóneo para ello, ya que no existen presiones comerciales o partidistas que limiten la libertad de expresión de los colaboradores, los cuales enriquecen el discurso universitario con tintes sociales y una frescura difícil de alcanzar en las emisoras convencionales, más preocupadas por el éxito de audiencia de sus programas.

Los datos obtenidos en este estudio demuestran que durante la temporada radiofónica 2014-2015 22 estaciones de radio universitarias españolas (casi el $100 \%$ de las asociadas a ARU) ya trabajaban de alguna manera el concepto de responsabilidad social en su programación, bien sea en forma de programas propios dedicados a contenidos sociales, o de espacios realizados por colectivos externos a la propia universidad, o mediante el apoyo a las actuaciones de asociaciones o ONG mediante la difusión de cuñas o promocionales en las parrillas universitarias. Y lo que resulta más reseñable es el continuo aumento, con respecto a los datos obtenidos en el estudio preliminar realizado durante el curso 2012-2013, en la que, la responsabilidad social solo se contemplaba en el $81 \%$ de los casos.

En cuanto a la manera en que se concreta la apuesta por la responsabilidad social de este tipo emisoras, podemos afirmar que la forma más habitual de introducir el mensaje en la parrilla de las radios universitarias es en forma de contenidos de índole social, suponiendo el $82 \%$ de los casos. En segundo lugar, apuntamos que el uso de cuñas sociales se sitúa como la siguiente forma de comunicación social más utilizada, suponiendo el $59 \%$ de los casos. En último lugar encontramos colaboración con organismos ligados a las propias universidades. 


\section{DISERTACIONES}

ESTUDIOS

Anuario electrónico de estudios en Comunicación Social ISSN: 1856-9536

Doi: dx.doi.org/10.12804/revistas.urosario.edu.co/disertaciones/a.4437

Volumen 10, Número 1/ Enero-junio 2017

Versión PDF para imprimir desde

http://revistas.urosario.edu.co/index.php/disertaciones

Con esta investigación hemos comprobado cómo en el curso 2012-2013, la mayoría de las estaciones analizadas han incorporado de alguna manera la responsabilidad social en sus actuaciones diarias, y han permitido que los futuros profesionales de la comunicación, en emisoras asociadas a titulaciones del área de las ciencias de la comunicación, contemplen como habitual y necesaria la colaboración con los ciudadanos y las personas del entorno social, para construir un discurso radiofónico sin intereses políticos ni comerciales, algo que está por fuera del alcance de las emisoras que forman parte del primer y del segundo sector de la comunicación.

\section{Referencias}

1. Aguaded, J. y Contreras, P. (2011). La radio universitaria como servicio público. Modelos de programación. En Autores, La radio universitaria como servicio público para una ciudadanía democrática. (pp. 3-11). La Coruña: Netbiblo.

2. Aguaded, J. y Martín-Pena, D. (diciembre, 2013). Educomunicación y radios universitarias: panorama internacional y perspectivas futuras. Revista Latinoamericana de Comunicación Chasqui, (124), 63-70.

3. Antequera, J. y Obregón, R. (julio, 2002). La radio como dinamizadora de procesos sociales y culturales en Barranquilla (Colombia). Investigación y Desarrollo, 10(2), 146-169.

4. Asociación de Radios Universitarias de España. (s.f.). Asociación de Radios Universitarias de España. Madrid: OndaCampus. Recuperado de http://www.asociacionderadiosuniversitarias.es

5. Barranquero, A. (junio, 2012). De la comunicación para el desarrollo a la justicia ecosocial y el buen vivir. Cuadernos de información y comunicación, 17, 63-78.

6. Casajús, L. (2011). Radio universitaria en América Latina: escenarios y perspectivas. En J. Aguaded. y P. Contreras. (eds.), La radio universitaria como servicio público para una ciudadanía democrática. (pp. 70-81). La Coruña: Netbiblo.

7. Casas, M. (noviembre, 2005). Nueva universidad ante la sociedad del conocimiento. Revista de Universidad y Sociedad del Conocimiento, 2(2), 1-17.

8. Contreras, P. (2012). La voz de los presos en la radio universitaria: puentes con la ciudadanía. La experiencia de UniRadio, Universidad de Huelva. En C. Espino. y D. Martín-Pena. (eds.), Las radios universitarias, más allá de la radio. Las TIC como recursos de interacción radiofónica. (pp. 153-165). Barcelona: UOC.

9. Contreras, P., González-Mariena, M. y Aguaded, J. (enero, 2014). Programar una radio social en la universidad: el propósito penélope de UniRadio. EDMETIC, Revista de Educación Mediática y TIC, 3(1), 112-130.

10. Chaparro, M. (2004). La radio asociativa y comunitaria. En M. Martínez-Costa. y E. Moreno. (eds.), Programación radiofónica. Arte y técnica del diálogo entre la radio y su audiencia. (pp. 293-320). Barcelona: Ariel.

11. Cheval, J. y Sevilla, S. (septiembre-diciembre, 2009). Diversite culturelle, interculturalite et radios associatives en france, l'exemple bordelais. Revista de economía política de las tecnologías de la información y comunicación, (3), 1-20.

12. Durán, Á. (junio-agosto, 2011). Las escasas posibilidades de la radio sin ánimo de lucro ante la Ley General Audiovisual. La incomprensible marginación de las emisoras universitarias públicas. Derecom Nueva Época, (6), 1-27. 


\section{DISERTACIONES}

ESTUDIOS

Anuario electrónico de estudios en Comunicación Social ISSN: 1856-9536

Doi: dx.doi.org/10.12804/revistas.urosario.edu.co/disertaciones/a.4437

Volumen 10, Número 1 / Enero-junio 2017

Versión PDF para imprimir desde

http://revistas.urosario.edu.co/index.php/disertaciones

13. Durán, Á. y Fernández, F. (marzo, 2005). La radio universitaria, entre la generalidad y la especialización. El caso de Vox UJI Radio. En A. Marín (Presidencia), II Congreso Iberoamericano de Comunicación Universitaria, Granada, España.

14. Gaete, R. (mayo-agosto, 2011). La responsabilidad social universitaria como desafío para la gestión estratégica de la educación superior: el caso de España. Revista de Educación, (355), 109-133.

15. García, J. (mayo, 2013). Transformaciones en el tercer sector: el caso de las radios comunitarias en España. Revista científica de estrategias, tendencias e innovación en comunicación, (5), 111-31.

16. García, M. (noviembre, 2012). Repensar la comunicación para la paz y la solidaridad desde lo participativo. Claves y propuestas. Razón y Palabra, (81), s/p.

17. González-Mairena, M. y Ramos, A. (2012). La audiencia en los debates radiofónicos a través de Facebook. La experiencia de UniRadio, Universidad de Huelva. En C. Espino y D. Martín-Pena. (coords.), Las radios universitarias, más allá de la radio. Las TIC como recursos de interacción radiofónica. (pp. 229-243). Barcelona: UOC.

18. López, M. (marzo, 2005). La construcción de la identidad a través de la radio digital universitaria. En A. Marín (Presidencia), II Congreso Iberoamericano de Comunicación Universitaria, Granada, España.

19. Marta-Lazo, C. y Marín-Pena, D. (enero, 2014). Antecedentes, estado de la cuestión y prospectiva de las Radios Universitarias. EDMETIC, Revista de Educación Mediática y TIC, 3(1), 1-6.

20. Martín-Pena, D. (2013). Radios universitarias en España: plataformas de comunicación interactiva y redes de colaboración. (Tesis doctoral inédita). Universidad de Huelva, Huelva.

21. Martín-Pena, D. y Contreras, P. (2014). Las radios universitarias en España: inicios, evolución y panorama actual. En Martín-Pena, D. y M. Ortiz. (coords.), Radios universitarias en América y Europa. (pp. 88-100). Madrid: Fragua.

22. Martín-Pena, D. y Espino, C. (septiembre, 2014). Contenido, estructura y función social en la programación de las radios universitarias. EDMETIC, Revista de educación mediática y TIC, 3(1), 29-43.

23. Merayo, A. (2000). Identidad, sentido y uso de la radio educativa. III Congreso Internacional Cultura y Medios de Comunicación. Salamanca: Ediciones Universidad Pontificia de Salamanca.

24. Milito, C. y Casajús, L. (junio, 2011). Las radios universitarias argentinas en Internet: relevamiento, desarrollos, modelos y enfoques. Question, 1(30). 2-17.

25. Ortiz, M. (noviembre, 2014). La radio como medio para la comunicación alternativa y la participación del tercer sector en España y Francia. Comunicación y hombre, 10, 25-36.

26. Peñafiel, C. (2011). 25 años de radio autonómica: un modelo de radiodifusión identitario y estable. En M. Ortiz. y López, N. (coords.), Radio 3.0. Una nueva radio para una nueva era. (pp. 67-88). Madrid: Fragua.

27. Pinto-Zúñiga, R. (2015). Estudio comparativo de las radios universitarias en Andalucía. En C. Mateos. y J. Herrero. (coords.), La pantalla insomne. Cuaderno artesano de comunicación. (pp. 2556-2569). España: Universidad de La Laguna.

28. Pinto-Zúñiga, R. (2016). Las radios universitarias en Andalucía: experiencias y nuevos retos. En D. Martín-Pena., C. Marta. y M. Ortiz. (coords.), La pantalla insomne. Cuaderno Artesano de Comunicación. España: Universidad de La Laguna. 
29. Radio Universidad Nacional de la Plata. (2009). Radio Universidad Nacional de La Plata. Argentina: Universidad Nacional de La Plata. Recuperado de https://www.radiouniversidad.unlp.edu.ar/institucional/

30. Rotman, A. (2014). Las radios universitarias argentinas frente a un nuevo paradigma de la comunicación. En D. Martín-Pena. y M. Ortiz. (coords.), Radios universitarias en América y Europa. (pp. 39-46). Madrid: Fragua.

31. Vázquez, M. (2012). La radio universitaria en México y España. Estudio de la participación y formación de los jóvenes. (Tesis doctoral). Recuperado de http://www.tdx.cat/handle/10803/84113

32. Universidad Nacional de Córdoba. (2006). La reforma universitaria de 1918. Argentina: Prosecretaría de Comunicación e Informática de la UNC. Recuperado de http://www.unc.edu.ar/sobre-la-unc/historia/ reforma 